4 IIKE
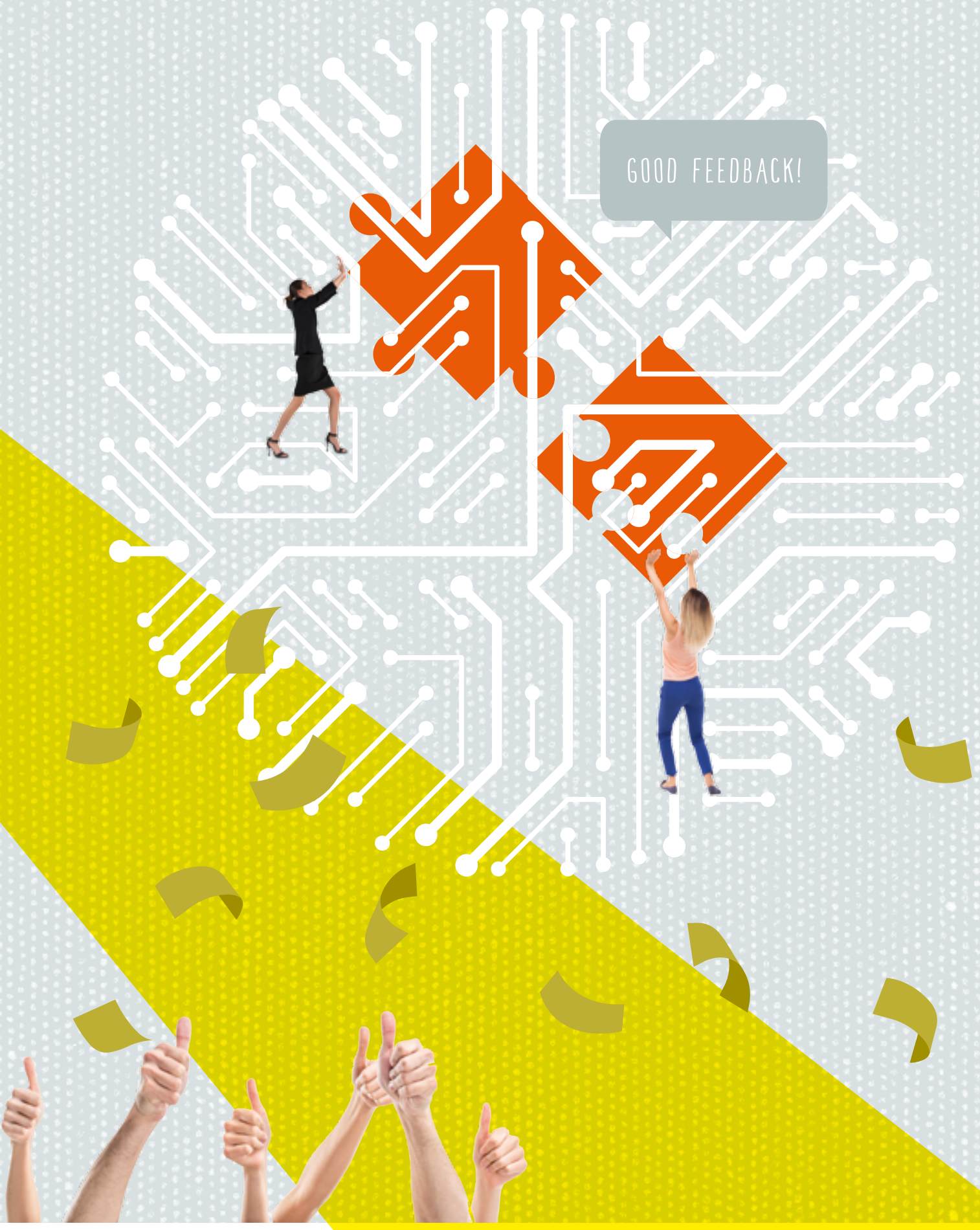


\title{
Platform Business: From Resources to Relationships
}

\author{
Marshall Van Alstyne and Geoffrey Parker
}

\author{
- \\ KEYWORDS \\ Platforms, Network Effects, \\ Digital Transformation, Internet Economy \\ THE AUTHORS \\ Marshall Van Alstyne, \\ Professor \& Department Chair, \\ Information Systems, \\ Boston University, Boston, MA, USA \\ mva@bu.edu \\ Geoffrey Parker, \\ Professor, Thayer School of Engineering, \\ Dartmouth College, Hanover, NH, USA \\ geoffrey.g.parker@dartmouth.edu
}

From Standard Oil to Google /// Over time, business success patterns have changed. The engine of industrial era giants such as Carnegie Steel, Standard Oil and General Electric was supply-side economies of scale. These companies achieved market power by controlling high fixed cost resources, by ruthlessly increasing efficiency and by extending their customer bases with competitive prices. Ever since the industrial revolution, a central strategy has been to build a moat around the business that protects it from competition. At the end of the last century, highly successful companies like Coca-Cola, Procter \& Gamble and Nike still functioned with this pipeline model of business, controlling a linear series of activities mostly within their own companies - the classic value chain. By investing heavily in mass communication and brand building, however, they stimulated demand and focused more on the power of consumers. Since the beginning of the 21st century, fueled by information technology and the internet, the demand side has become even more important and has, in fact, turned the basic business principles of resource-based pipeline thinking upside down. The new giants, Google, Facebook, Apple, Amazon and the like, function differently.

Online platforms and the network effect /// The driving force behind our internet economy is now demand-side economies of scale, also known as network effects. These arise when users create value for other users. They are enhanced by technologies that create efficiencies in social networking, by demand aggregation, by app development and by other network-expanding activities. In the internet economy those companies that achieve higher volume than competitors by attracting more platform participants are able to offer a higher average value per transaction: The larger the network, 
FIGURE 1:

Players and their roles in platform business

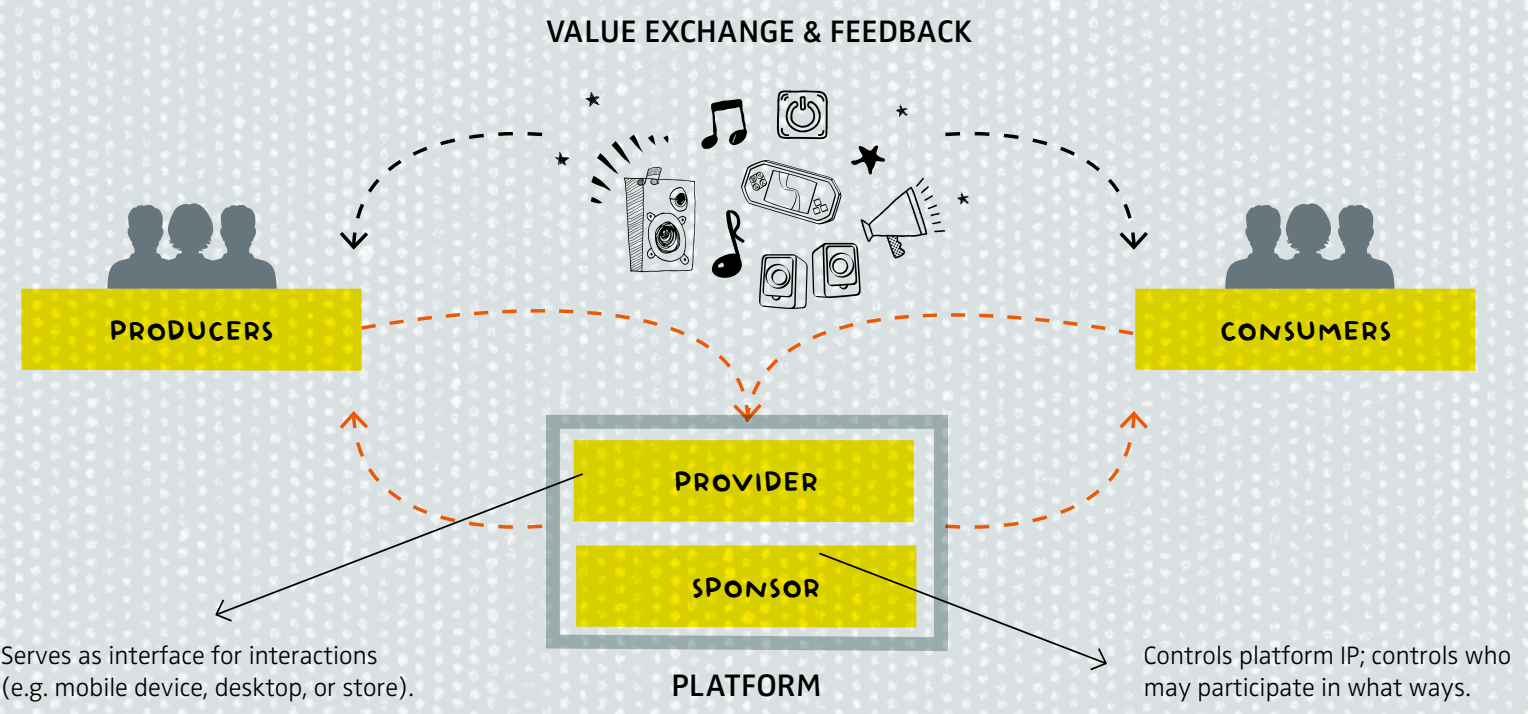

the better the matches between supply and demand and the richer the data that can be used to find matches. As users create value for users, value spirals upward, attracting further users. Network effects gave us Alibaba, which accounts for over $75 \%$ of Chinese e-commerce transactions; Google, which accounts for $82 \%$ of mobile operating systems and $94 \%$ of mobile search; and Facebook, the world's dominant social platform. Platform business has turned the traditional logic of success inside out and has established new rules for success. The reason is simple: Network effects cannot scale inside a company as easily as they do outside. This means that value-creating activities that used to take place inside must now also take place outside companies.

$\gg$

\section{Value-creating activities that used}

to take place inside must now also take place outside companies.
How platform strategies work /// Platform businesses bring together producers and consumers in efficient exchanges of value, and they have always existed: Markets and malls link consumers and merchants, newspapers connect subscribers and advertisers, while travel agencies match tourists with trips. What has changed in the past few years is that, by reducing transaction costs, information technology has profoundly reduced the need to own physical infrastructure and assets. Uber, for example, connects drivers and riders without owning any cars, while Airbnb connects hosts and guests without owning any rooms. Walmart has one of the best inventory management and logistics operations in the world, but Alibaba has grown more valuable without owning any inventory at all.

The main asset of a platform is its network of producers and consumers. In contrast to pipeline strategies, resource orchestration is more important than resource control, and facilitating interactions and managing relationships have a higher priority than internal optimization. Successful platforms seek to maximize the overall value of the whole system in a circular, revolving and feedback-driven process.

Though they come in many varieties, platforms all have an ecosystem with the same basic structure, comprising four types of roles. The owners of platforms control their intel- 
$\{$ Box 1$\}$

\section{APPLE: PLATFORM + PIPELINE}

When the iPhone was released in 2007, Apple was a newcomer to the mobile phone market. Seven stable, profitable brands like Nokia, Motorola, Samsung, Sony Ericsson, Blackberry and LG controlled $90 \%$ of all handset profits. But within a few years these seemingly entrenched brands were fighting for survival. By 2015 the iPhone generated $92 \%$ of global profits, while all but one of the former incumbents made no profit at all. By the end of 2016, Nokia and Blackberry combined had less than $1 \%$ market share.

How can we explain the iPhone's rapid domination of its industry? Certainly the iPhone had an innovative design and novel capabilities. But that's not the real driver. Apple (along with Google's competing Android system) overran the incumbents by exploiting the power of platforms and leveraging the new rules of a platform strategy. Apple built a platform on top of a product. The iPhone, its operating system and its iTunes store became a conduit for services, connecting participants in two-sided markets - app developers on one side and app users on the other - generating value for both groups. As the number of participants on each side grew, that value increased - a phenomenon called "network effects," which is central to platform strategy. By January 2015, the company's app store offered 1.4 million apps and had cumulatively generated US\$25 billion for developers.

Apple managed to build a platform business together with a conventional product business: running the app store as well as producing phones and other hardware. Apple shows that companies need not be only a pipeline or a platform; they can be both.
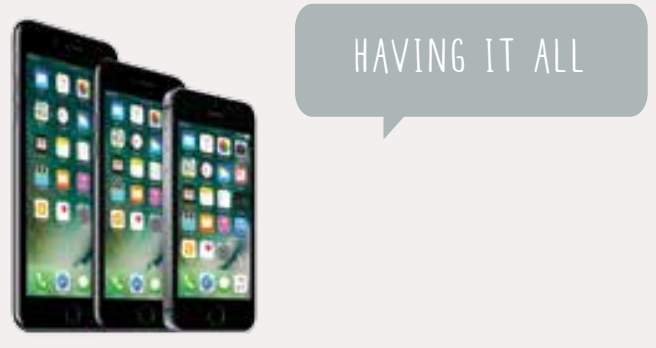

lectual property (IP) and governance. Providers serve as the platforms' interface with users. Producers create their offerings, and consumers use those offerings. The players might rapidly swap roles or play several roles simultaneously. For instance, users can ride with Uber today and drive for it tomorrow; travelers can stay with Airbnb one night and serve as hosts for other customers the next. Apple provides both the handset and the IP for the iPhone while Google focuses on the IP and lets others provide the handset. Understanding the relationships both within and outside the platform ecosystem is crucial to platform strategy.
The expansive power of platforms /// Successful platform businesses tend to move aggressively into new terrain and reframe traditional industries in new ways with little warning. Google has moved from web search into mapping, mobile operating systems, home automation, driverless cars and voice recognition. As a result of this kind of shapeshifting, a platform can abruptly transform an incumbent's set of competitors as well as established rules and success factors within an industry. 
FIGURE 2:

How networks enter new markets

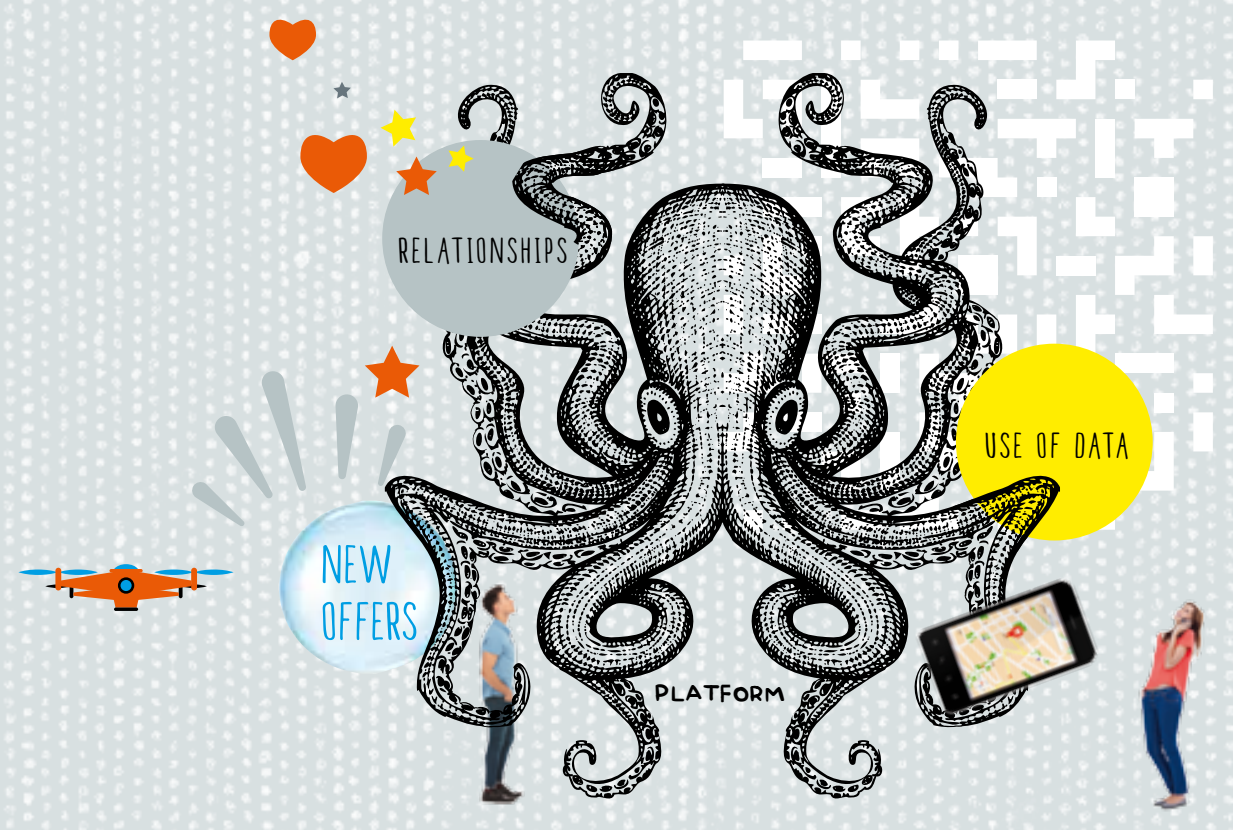

Expansion can be fueled by strong relationships within the network. With one foot in the door of a huge customer base, it is fairly easy to expand into new fields, like Google is doing in home automation. Some platforms create new offers, like Uber or Airbnb, attracting customers away from more traditional products. The data collected by platforms can also open doors to new markets - and confront incumbents with new competition - at least in some of the segments they serve.

Successful platforms put companies using traditional business models at risk. Swatch knows how to compete with Timex on watches but now also has to compete with Apple. BMW knows how to compete with Ford in automobiles but now is being challenged by Uber. To survive in an increasingly platform-dominated business environment, traditional companies need imagination, a new mindset, new competences and new leadership styles. Plenty of pure pipeline businesses are still highly competitive, but when platforms enter the same marketplace, the platforms usually win. Companies that fail to create platforms on their own or integrate their business into existing platforms are likely to face increasing pressure on their margins as they compete against businesses that can harness multiple revenue streams.
How to govern platforms successfully /// The success of platform businesses like Alibaba, Airbnb and Uber is so remarkable that discussion about them often misses just how hard they are to build. For every successful platform, there are many more that struggle or simply don't make it. And even Apple and Google, two of the world's most valuable companies, have had their share of platform failures. Studying success and failure, we identified the following key success factors:

\section{Successful platforms seek to maximize the} overall value of the whole system in a circular, revolving and feedback-driven process.

$$
\text { 《 }
$$


$>$ Find the right extent of openness /// Platform owners need to define - and adapt over time - how open they want to be to possible players and how much freedom these will have in framing their interactions with others. If platforms are too closed, the number of participants might be too small to generate attractive network effects. If they are too open, there might be value-destroying effects, such as poor quality contributions or misbehavior that cause others to defect. To be open and ensure quality, Airbnb and Uber use ratings, Twitter and Facebook provide users with tools to prevent stalking and Apple's app store and Google Play both filter out low-quality applications.

$>$ Launch small and with the right side /// Most successful platforms launch with a single type of interaction that generates high value even if, at first, it produces low volume. They then move into adjacent markets or adjacent types of interactions, increasing both value and volume. Facebook, for example, launched with a narrow focus connecting students within Harvard and then opened the platform to college students broadly and ultimately to everyone. Platform managers also have to carefully determine which side of the platform market to emphasize and when to do so. Sometimes at launch it's important to focus on attracting consumers over producers; sometimes it's the reverse, and sometime both sides need equal attention from the outset.

$>$ Focus on critical mass and quality ahead of money /// If platform monetization comes at the expense of building network effects, it should wait. A critical mass of users is a precondition for creating value at scale. Therefore, other metrics than the traditional financial measures are relevant to assess a platform's success and potential. Beside the number of participants and interactions, metrics like engagement, interaction failure or match quality should be defined and monitored.

$>$ Create real value and share it fairly with all participants /// To create value, committed software developers need to be attracted. They need resources to create a great and valued platform experience. Having valuable interactions is the reason for all players to participate on a platform. The consumer, the producer and the platform all win if the division of value works for everyone. If one party gets insufficient value, they have no reason to stay on board. A simple rule for platform managers is to take less value than they make and to share value fairly with all participants.
In the end, platforms are about relationships. With better relationships come more interactions and with more interactions come more network effects. Orchestrating the value from these interactions is the art of shifting from products to platforms.

l.

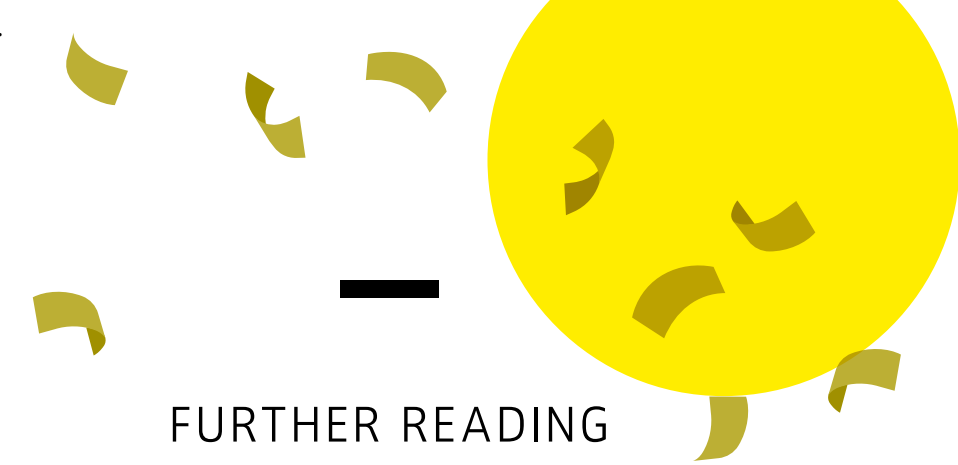

Eisenmann, T.; Parker, G. G; Van Alstyne M. W. (2006):

"Strategies for Two Sided Markets,"

Harvard Business Review, Vol. 84 (10), pp. 92 - 101.

Van Alstyne, M. W.; Parker, G. G., and Choudary, S. P. (2016):

"Pipelines, Platforms, and the New Rules of Strategy,"

Harvard Business Review, Vol. 94 (4), pp.54-62.

Van Alstyne, M. W.; Parker, G. G., and Choudary, S. P. (2016):

“6 Reasons Platforms Fail,” Harvard Business Review Digital Article,

https://hbr.org/2016/03/6-reasons-platforms-fail

Parker, G. G.; Van Alstyne, M. W.; Jiang, X., (2017): "Platform Ecosystems: How Developers Invert the Firm," MIS Quarterly, Vol. 41 (1), pp. 255-266.

Parker, G. G.; Van Alstyne, M. W.; Choudary, S. P., (2016):

"Platform Revolution: How Networked Markets Are Transforming the Economy-And How to Make Them Work for You," Norton \& Company 